\title{
Bioética global: ¿nuevos argumentos sobre los derechos animales?
}

\section{Global Bioethics: \\ ¿New arguments on animals' rights?}

\author{
José Enrique Gómez Álvarez*
}

https://doi.org/10.36105/mye.2022v33n1.03

\section{Resumen}

El artículo aborda algunas variantes recientes de los argumentos a favor de un posible derecho de los animales. Para lograr este objetivo se hizo una muestra por conveniencia de artículos en los que apareciesen ambos conceptos desde el año 2017 hasta el presente, usando el buscador Google Académico (Google Scholar). De la muestra (primeros 40 resultados de búsqueda) se seleccionaron los que resumiesen o presentasen algún argumento novedoso en torno al tema. Después del análisis se encontraron básicamente dos argumentos que pueden presentarse como novedosos pero que, al analizar los presupuestos de los mismos, se concluye que presentan los mismos supuestos ontológicos que los argumentos tradicionales, como los de Peter Singer.

Palabras clave: ontología, bioética global, argumento desacreditador, madre Tierra.

\footnotetext{
* Centro de Investigación Social Avanzada (CISAV). Querétaro, México. Correo electrónico: jegomezalvarez@yahoo.com https://orcid.org/0000-0002-8964-2207 Recepción: 15 de agosto de 2021. Aceptación: 12 de septiembre de 2021.
}

Medicina y Ética - Enero-Marzo 2022 - Vol. 33 - Núm. 1 


\section{Bioética global y los animales}

El término «bioética global» es un término en disputa. A algunos autores el término «bioética» les sugiere que, desde un punto de vista práctico, significa que los que lo utilizan deberían asumir conductas académicas «semejantes» tanto en temas, fuentes usadas y comunicación con otros investigadores. Así, Holm y Williams-Jones, en «Global bioethics-myth or reality?» (1), apuntan que incluso investigadores y bioeticistas de países «afines» por el lenguaje y la cultura, como Canadá, EUA e Inglaterra, en la práctica no siguen (casi) los mismos autores, consumen bibliografía diferente en temas de bioética y consultan sitios web no comunes. Ellos, desde un enfoque social, sostienen que:

Nuestros tres estudios exploratorios de patrones de comportamiento en el campo de la bioética apoyan la posición de que, de hecho, no existe un campo global unificado de la bioética. Parece que, incluso en los países de habla inglesa, los especialistas en bioética no se vinculan a los sitios web de los demás tanto como se esperaría, no se citan entre sí tanto como se esperaría y no convergen en los mismos libros tanto como lo harían si la bioética fuera verdaderamente un campo «global» (1).

Por tanto, al menos en un sentido de la «bioética global» hay evidencia de que no se cumple la expectativa de ética común; es decir, la interrelación entre pensadores no es tan fuerte como pareciera. Además de la situación expuesta en los autores anglosajones, la interrelación con otros autores de distintos idiomas es escasa. Por supuesto, la barrera del idioma es una explicación (2), aunque parece que también, en opinión de estos mismos autores citados, se produce un cierto localismo: se citan y estudian los que ellos conocen o son accesibles (1). En este sentido, el uso de «bioética global» no parece ser del todo correcto.

Otros autores defienden que la «bioética global» puede referirse a una unidad de principios comunes (3). En ese sentido, la bioética de los principios, al ser dominante en el mundo occidental, al me- 
nos mostraría que hay una cierta unidad metodológica y doctrinal en torno a los cuatro principios de Beauchamp y Childress. Otro sentido de bioética global es el expresado por Potter, ante el cual Vargas señala que:

...pone el acento en la necesidad de construir un puente hacia el futuro que permita en el largo plazo la supervivencia de la especie humana. Para Potter, la separación entre la ciencia y las humanidades constituye un problema que puede poner en riesgo la vida en el planeta. Esta idea, que busca unir el conocimiento científico y las humanidades, es la que expresa mejor la metáfora de puente. Sin embargo, esta metáfora contiene otro significado adicional...; el doble significado de la palabra «puente» tiene, por un lado, un componente de unidad (entre las ciencias y las humanidades) y, por otro, un llamado a superar los problemas que ponen en riesgo el futuro de la especie humana (4).

Otros autores (5) señalan que hay cuatro sentidos de la noción de «puente»: una conexión entre el presente y el pasado, en donde se garantice la supervivencia humana (y la del planeta); puente entre ciencia y valores; puente entre naturaleza y cultura, y puente entre seres humanos y naturaleza (la ecología).

Lo que aquí interesa es que esa consideración de la supervivencia humana implica la pregunta de cómo debemos comportarnos los seres humanos frente a los animales. Desde hace décadas se ha defendido que los animales (no humanos) poseen derechos como nosotros. La pregunta que puede uno hacerse es: ¿han cambiado en algo los argumentos al respecto? ¿Cuáles son los argumentos más recientes?

Para contestar esta pregunta se realizó una muestra documental por conveniencia en Google Académico desde 2017 hasta la fecha, en la que se relacionó «ética global» y «animales». Del resultado de la búsqueda se seleccionaron los artículos que exponen argumentos a favor y en contra sobre los supuestos derechos de los animales. Aquí se reseñan los argumentos encontrados y se comentan dos de ellos que agregan o intentan agregar algo nuevo al debate.

Medicina y Ética - Enero-Marzo 2022 - Vol. 33 - Núm. 1 


\section{Un antecedente: Paul Max Fritz Jahr $(5,6,7)$}

La idea central de este teólogo, aparte de concebir y utilizar el término de «bioética», es la de incluir a los animales dentro de las cadenas de vivientes semejantes al ser humano. Jahr, en pocas palabras, se opone a Descartes y a su mecanicismo respecto de los animales. Comenta que la cultura oriental reconoce una naturaleza espiritual a los animales que requieren respeto y cuidado (6). No obstante, señala las diferencias con Occidente, al comentar el carácter utilitario del uso de las plantas y animales y de su protección limitada en cuanto a nuestro beneficio. Sin embargo, defiende una reformulación del imperativo categórico de Kant, en donde de algún modo se incluyen a los animales y a las plantas. $\mathrm{Al}$ final de su ensayo, Jahr señala:

Pero estamos progresando y la protección de los animales gana terreno, disponiendo de un espacio cada vez más amplio. Del mismo modo, un hombre decente ya no tolera que se destruyan flores o que un niño travieso las arranque de un jardín para luego tirarlas negligentemente.

Nuestra autoeducación ha hecho muchos adelantos, pero debemos seguir desarrollándola de manera que adoptemos como pauta de exigencia bioética para nuestra conducta el siguiente principio: $¡$ Considera a cada ser viviente como un fin en sí mismo y trátalo, de ser posible, como tal! (6).

Por supuesto, la indicación final señala una cierta limitación: «en cuanto sea posible», la cual deja abierta la cuestión de cuánto debe persistir el criterio utilitario en el cuidado de los animales. Está claro qué debemos elegir en una colisión de intereses prioritarios. Jahr, en otro escrito, Tres estudios sobre el quinto mandamiento (7), señala que el «no matarás» no hace alusión sólo a la vida humana, sino a todos los vivientes. Si fisiológica y psicológicamente los animales son semejantes a nosotros, entonces, ¿no debemos respetarlos igual? Claro, así lo hace notar Jahr; los derechos animales podrían no ser los mismos, sino en proporción al ser que se aplican. En 
Bioética global: ¿nuevos argumentos sobre los derechos animales?

este sentido, los animales no deben ser torturados sin razón alguna. Por supuesto, en un sentido, aquí no hay mucha diferencia con la defensa tradicional de que en el hombre se produce un salto cualitativo respecto de los demás vivientes, pero no implica un dominio sin límites sobre ellos. El hombre debe tratar a los animales y plantas con un carácter de tutela, aunque sin dejar de tener un señorío o dominio sobre ellos. En este sentido no hay conflicto aparente. Así, por ejemplo, la Iglesia católica, en palabras del papa Francisco, puede afirmar: En esta linea, cabe reconocer que nuestro propio cuerpo nos sitúa en una relación directa con el ambiente y con los demás seres vivientes. La aceptación del propio cuerpo como don de Dios es necesaria para acoger y aceptar el mundo entero como regalo del Padre y casa común, mientras que una lógica de dominio sobre el propio cuerpo se transforma en una lógica a veces sutil de dominio sobre la creación (10). Un modo de interpretar el pasaje anterior es comprender que el dominio humano no es despótico. $\mathrm{Al}$ reconocer que hay una naturaleza en nosotros que debe respetarse esto ayuda a entender que la naturaleza no humana señala también límites a nuestra libertad. Otro sentido de la teología de Jahr acercaría a las posturas que defienden que los animales no humanos merecen la misma consideración de cuidado, aun cuando haya diferencias radicales en cuanto a las capacidades (4).

El pensamiento de Jahr contrasta con la posición de Tomás de Aquino, que se plantea una cuestión semejante. Tomás escribe que el homicidio es pecado porque priva al hombre de la vida. Pero la vida es común a los animales y a las plantas. Luego, por la misma razón, parece ser pecado matar a los animales brutos y a las plantas (11). Pero la respuesta de Tomás a la objeción muestra la distancia entre el pensamiento clásico y el de Jahr: los animales no son racionales y hay un cierto orden entre animales y plantas que permite utilizarlos en nuestro beneficio. Hay que notar que Tomás no niega que los animales tengan en común algo con los humanos, como el carácter sentiente, pero la radicalidad propia del hombre, que es ser personal, permite el «uso» de los animales y de las plantas, así como los animales

Medicina y Ética - Enero-Marzo 2022 - Vol. 33 - Núm. 1 
«usan» las plantas. En pocas palabras, los animales no humanos y las plantas no son fines en sí mismas, como lo son los seres humanos.

Los defensores de los derechos de los animales no humanos insistirían en que no basta tratarlos con cuidado, sino que es necesario reconocerles derechos intrínsecos y no derivados de la conducta y naturaleza humana. Dicho de otro modo, es preciso reconocerles derechos animales como nosotros reconocemos derechos humanos. La bioética de Jahr:

...parte de una concepción biologicista que postula una continuidad fundamental entre las plantas, los animales y el hombre. Esta continuidad no niega cierta diferenciación, admitida también por Darwin, en razón del sentido moral o de la conciencia en el hombre. Pero tal diferenciación se reduce, en última instancia, a la del movimiento respecto de su propio término. El ser humano sería diferente solamente porque es el punto más alto de un proceso evolutivo que comprende al conjunto de los seres vivos (5).

Se concluye, así, que la diferencia entre seres humanos y animales es sólo de grado. Esa concepción es el presupuesto central que aparece en los argumentos recientes sobre los animales y que en esencia no marca una diferencia especial con los argumentos tradicionales de los «derechos de los animales» $(4,12)$.

\section{Derechos de los animales: un argumento común}

Al revisar la literatura en castellano se encuentran referencias a los argumentos de autores anglosajones a favor y en contra de supuestos deberes (derechos) de los animales $(13,4)$. Así, es común citar la postura de Singer (4). Básicamente hay dos ideas que se repiten en los argumentos: el especismo es igual que el racismo, el sexismo o el viejismo; es decir, son discriminaciones indebidas. El otro argumento es el de la superposición de las especies: es posible mostrar que, en realidad, en términos de capacidades, los humanos y los animales a veces están al mismo nivel. En realidad, ambos argu- 
mentos poseen un elemento común: no hay salto cualitativo entre los seres humanos y los animales (1). Se pueden sintetizar ambos argumentos del siguiente modo:

1. Toda discriminación basada en características irrelevantes para la distinción entre una entidad personal y una no personal es un acto moralmente indebido.

2. El sostener superioridad por pertenecer a otra especie es discriminación basada en características irrelevantes.

3. Por lo tanto, el sostener superioridad por pertenecer a otra especie es un acto moralmente indebido.

La premisa 1 parece razonable y, de hecho, como señala Singer, se terminó reconociendo que era un error en las situaciones como el color de la piel (racismo) o la sexualidad (sexismo). Pero es claro que la clave del argumento es la noción de persona, que es un supuesto de la premisa (2). Singer insistirá en que la noción de persona es una característica empírica atribuible en el transcurso de la vida y que no está presente sólo en la especie humana. En ese sentido, cuando «aparecen», por ejemplo, los atributos de «autoconsciencia» y «visión del futuro» es cuando se puede decir que existen las personas. Singer ve la persona no desde un punto de visto ontológico, sino meramente fenoménico: se dispone de la capacidad sólo cuando se hace manifiesta de un modo semejante a andar en bicicleta. Sólo podemos tener esa habilidad cuando se da, cuando se hace manifiesta. En consecuencia, con el argumento anterior sólo cuando una persona expresa en un lenguaje articulado que su vida vale y puede visualizar o expresar deseos en tiempo futuro es persona en «ese momento». Ser persona, pues, es una manifestación de habilidades que le adjudicamos a la palabra «persona»; es decir, una postura nominalista, actualista y funcionalista de la persona. Por tanto, los embriones y quizás los niños muy pequeños no son personas.

Se ha objetado que esa visión de las capacidades es errónea. Las capacidades humanas son radicales o, dicho de otro modo, hay una capacidad radical que clásicamente se ha señalado como la inteligencia y la voluntad, que están dadas desde el inicio de la existencia. 
La inteligencia y la voluntad son capacidades para aprender habilidades. Sin esa capacidad radical no se podría tener la inteligencia humana con su capacidad de conocer universal e inmaterialmente. Así, «inteligencia» en los animales no se dice en el mismo sentido que en las personas (11), ya que podría explicarse más bien como instinto, por semejante que parezcan sus actos a los humanos.

En otros términos, los seres humanos tenemos una capacidad radical para adquirir habilidades: capaz de» debe entenderse como la posesión de una naturaleza cuya manifestación plena permite realizar tal valoración (valorar la propia existencia), independientemente de que el individuo se encuentre o no en posibilidades de ejercer esa capacidad (14). Valorar la existencia no es sólo una cuestión de tener más o menos estados conscientes de placer o dolor, sino la capacidad de visualizar, por ejemplo, estados futuros posibles y una capacidad de abstracción y de conocer lo universal que implican una naturaleza radicalmente distinta.

En la sección $\mathrm{V}$ comento un poco más esta peculiaridad humana que Singer y otros autores consideran inexistente.

\section{4. ¿Un nuevo argumento?}

France Jacquet, en «A debunking argument against speciesism» (15), publicado este 2021, propone un nuevo modo de refutar a los especistas: ...propongo una perspectiva novedosa en este tema desarrollando un argumento de desacreditación contra el especismo (15).

El profesor Jacquet parte de la idea de que nuestros razonamientos morales se configuran y reconfiguran, al comparar nuestras intuiciones morales entre sí y con la propia experiencia. Dicho de otro modo, tenemos un principio intuido; por ejemplo, «mientras no se haga daño físico a alguien, una acción es lícita (moralmente)» y después, al comparar nuestra intuición con la realidad, descubrimos el incesto como una práctica «que no hace daño físico», y si consideramos intuitivamente que el incesto es malo, pues colisiona con la intuición original, ya que se produce una clara con- 
tradicción: tenemos un caso particular afirmativo que se considera verdadero (alguna práctica que no hace daño físico es mala) que entra en conflicto con el principio universal negativo (toda práctica que no hace daño físico no es mala). Esa contradicción nos lleva a reformular nuestras intuiciones morales.

En el caso de los animales, el autor cree que es el mismo caso y pone como ejemplo el argumento ya citado de Singer. Se tiene una intuición moral fundamental: el racismo, sexismo y otras diferencias son irrelevantes para el trato que deben recibir las personas. En cambio, con los animales (no humanos) hacemos distinción de trato sólo por la pertenencia a la especie, pero:

...un número de humanos están psicológicamente a la par con algunos animales no humanos, o incluso son inferiores a ellos en esas capacidades. Compárense, por ejemplo, las personas severamente discapacitadas en el aspecto mental con simios adultos. En consecuencia, esas diferencias psicológicas no separan a todos los humanos de todos los no humanos...; la diferencia de las especies es meramente biológica (15).

De nuevo, el argumento supone que las capacidades radicales humanas no existen como tales, sino sólo aparecen y desaparecen habilidades que en sí mismas no son diferentes de los animales o, como lo dijimos antes, lo emergente humano se considera sólo una cuestión de grado. La evolución biológica desmiente la idea de una esencia humana «fija», idea que los objetores creen que anula el naturalismo ético de tipo aristotélico (16). La evolución desacredita (debunk) la teoría de una naturaleza humana fija.

El ejemplo previamente expuesto del incesto, que parece moralmente repugnante, ilustra el origen no moral de ciertas creencias «morales»: el incesto en realidad es un mecanismo producto de la evolución; es decir, el proceso evolutivo generó en las personas cierto rechazo de los padres para evitar la generación de seres humanos defectuosos, y permitió así la diseminación de los genes de los humanos; entonces, el origen de esta creencia moral es un elemento no moral, sino un hecho fáctico de la evolución. 
Un argumento desacreditante es un argumento cuyo propósito es «desmontar» una creencia moral, basado no en otras creencias morales, sino en la historia causal que muestra su injustificación, al mostrarse que en realidad no es un principio ético. La creencia moral es producida por un proceso desencaminado (off-track) respecto de lo moral. Así, el ejemplo del incesto, según este autor, al mostrar el origen «no moral» de la creencia, producto de un mecanismo evolutivo, lo desacredita. Es una idea que me parece extraña. El autor no la señala, pero parece ser un argumento que supone que produce la falacia naturalista: lo moral es deducido de un elemento puramente fáctico que no tiene que ver con el deber. Se rechaza que las tendencias humanas sean indicadores de un cierto orden normativo (17).

$\mathrm{Al}$ autor le parece irreconciliable una visión metafísica de finalidad y la evolución. Como es «evidente», la primera queda desacreditada por la segunda y se da por hecho que no existen las causas finales (18).

Ahora bien, al partir de la idea de disonancia cognitiva o, lo que es lo mismo, de la incongruencia entre nuestras acciones y nuestras creencias, se tiene que realizar algo para eliminar o neutralizar la disonancia. Así, por ejemplo, fumar y saber que el cigarro hace daño es un ejemplo de disonancia: no quiero hacerme daño, pero fumo y la única manera de solucionar la incongruencia es o dejar de fumar, o sea, cambiar la acción, o modificar mi creencia; por ejemplo, considerar que es mayor el beneficio de fumar el tabaco que el daño que me ocasiona.

¿Qué paradoja encontramos con respecto a los animales? Algunas personas que comen carne piensan que comer la carne de los animales hace daño a los animales (se entiende por daños innecesarios estar sin libertad en granjas de producción, por ejemplo). Tampoco es necesario comer carne para sobrevivir, ya que lastimar a los animales es malo moralmente; no obstante, estas personas siguen el hábito de comer carne, generando así una disonancia cognitiva. 
La paradoja de la carne, según el profesor France Jacquet, lleva a inconsistencias teóricas o a ajustes para evitar la disonancia cognitiva, ya sea:

a) Diciendo que los animales no sienten, por lo que no se les hace daño. Puede no ser necesario comer carne, pero no se les hace ningún daño (15).

b) Señalando que sí es necesario comer carne de animales (15).

Estas inconsistencias se incrementan en las situaciones en las que se presenta la oportunidad de comer carne de animales; es decir, las personas tienden a ser más especistas cuando se ven enfrentadas a la situación de ser carnívoras. Los especistas sostienen sus creencias, no por un proceso de aceptación de la verdad, sino por un ajuste de sus prejuicios. Dicho de otro modo, cuando se ven involucrados los intereses de los sujetos tienden a ser especistas. Así, los opositores a las peleas de perros o gallos se oponen a ellas cuando no participan en las mismas. Al momento de participar tienden a ajustar su disonancia cognitiva, pero no por un proceso racional, sino por un proceso desencaminado (offtrack). El autor señala que:

a) La creencia especista se explica por el intento de reducir la disonancia cognitiva.

b) El intento de reducir la disonancia cognitiva es un proceso desencaminado.

c) En consecuencia, la creencia especista es injustificada.

La primera premisa es mostrada por diversos datos empíricos que se señalan en el artículo, que muestran cómo la actitud especista se incrementa en las situaciones que tienen que ver con la alimentación (15). En el caso de la segunda premisa, la reducción de la disonancia cognitiva no es un proceso que rastrea la verdad de cómo debemos tratar a los animales..., sino que se debe a una influencia distorsionadora, a un factor no relacionado con su verdad (15).

La disonancia, pues, no es producto racional de búsqueda de la verdad, sino resultado de un proceso que podríamos llamar «apócrifo». El consumo de cárnicos se produce a pesar de creerse que es ilícito lastimar innecesariamente a los animales, por lo que la 
creencia se mantiene por razones psicológicas, como evitar el conflicto de intereses. En pocas palabras, es inconsistente al ser emotivo (voluntarista). Si no es racional y la otra opción es la no especista, parece razonable seleccionar la segunda opción que sí posee justificación racional. ¿'Por qué el vegetariano tiene razón? Pues porque no hay diferencia entre animales y hombres más que de grado, como se señaló en el argumento común. Es decir, a pesar de su aparente fortaleza, el argumento se fundamenta así o se da por bueno el argumento tradicional ya señalado en la sección II.

\section{Otro argumento reciente: el nuevo constitucionalismo latinoamericano $(18,19)$}

Las Constituciones de Ecuador y Bolivia han planteado introducir conceptos de la «ecología profunda» $(18,20)$, la cual tiene implicaciones para los animales. Dicho argumento podría esquematizarse así:

a) Si la naturaleza es reconocida como madre Tierra (como de hecho hacen las culturas originarias de Ecuador y Bolivia), entonces todos los organismos son interdependientes.

b) Si son interdependientes, entonces no hay jerarquía entre los vivientes. Por lo tanto,

c) Si la naturaleza es reconocida como madre Tierra, entonces no hay jerarquía entre los vivientes.

d) Los animales (incluido el hombre) son parte de la naturaleza reconocida como madre Tierra.

e) Entre los animales (incluido el hombre) no hay jerarquía entre ellos.

La segunda premisa es, sin duda, la más problemática. El hecho de la interdependencia es real, pero ¿eso implica que los seres humanos no están en la escala superior? A veces la ecología, con el afán de proteger la naturaleza más que alzarla, lo que produce es una reducción del hombre. 
Bioética global: ¿nuevos argumentos sobre los derechos animales?

La cuestión defendida es que ecológicamente el hombre no puede o debe dominar a los demás seres $(20,21)$. La naturaleza no humana no es un recurso más sujeto a la explotación. La naturaleza no humana, así, posee un valor independiente de la propia apreciación humana. El hombre habita en su casa común, la naturaleza, pero este habitar debe ser ajustado para reconocer ese valor intrínseco de lo natural. Las culturas originarias tenían claro, según esta postura, ese concepto:

Y así es como en ciertas regiones, principalmente indígenas, desde su cosmovisión han llegado a reconocer subjetivamente a la naturaleza como sujeto que merece cuidado y protección, con la finalidad de llegar a construir una relación de estabilidad recíproca humano-naturaleza, a la que podemos llamar una relación con un toque biocéntrico... Es una forma de retomar una conciencia holística e histórica del valor natural de la vida no humana, que rompe con el antropocentrismo convencional de la modernidad eurocéntrica (21).

La defensa de la segunda premisa implica que la complejidad del mundo natural impide poner al hombre en la cúspide. Las interrelaciones de supervivencia hacen que si a un ser se le pone «encima» de los demás, esto produce efectos disonantes en toda la naturaleza. Esos efectos disonantes serían prueba, por tanto, de que algo anda errado en la argumentación a favor de la primacía de lo humano.

De la cuarta premisa se deriva que debe haber un auténtico respeto hacia los animales. Por supuesto que esto tiene presupuestos ontológicos (20). Esos presupuestos ontológicos son: La capacidad de sufrir y de sentir placer es vital, además de un prerrequisito para que un ser se convierta en objeto de interés y, por consiguiente, la igualdad de consideración debe existir independiente de la especie (19).

En este contexto, prerrequisto equivale a presupuesto ontológico. Aceptado el mismo, cabe aplicar a los casos concretos. De nuevo surge la idea de la superposición de las especies: los animales no humanos sólo tienen diferencia de grado y la capacidad de sentir y sufrir es el criterio ético, en vez de la racionalidad y el autodominio

Medicina y Ética - Enero-Marzo 2022 - Vol. 33 - Núm. 1 
propios de lo humano. Por supuesto que puede irse más allá e incluso insistir en que también los elementos no sentientes y abióticos poseen derechos: los Derechos de la Madre Tierra o de la Naturaleza (Pachamama) (19).

El cuidado de la naturaleza no humana como parte de la responsabilidad humana es un tema que se requiere analizar aparte. Así, en la Declaración Universal de Bioética y Derechos Humanos se señala:

Se habrán de tener debidamente en cuenta la interconexión entre los seres humanos y las demás formas de vida; la importancia de un acceso apropiado a los recursos biológicos y genéticos y su utilización; el respeto del saber tradicional y el papel de los seres humanos en la protección del medio ambiente, de la biosfera y la biodiversidad (21).

La cuestión ontológica de fondo es, pues, el concepto de «nivelación ontológica» entre el hombre y la naturaleza, tal como plantean las teorías de la ecología utópica. Según ellas, no habría diferencia ontológica entre las plantas, animales y el hombre. Visto así, se justificaría la detención de la explotación de los recursos naturales por parte del hombre, en cuanto afecta la «dignidad» de los otros seres vivos. No obstante, la verdad del movimiento ecologista se basa en que la relación del hombre con los demás vivientes no se puede ver como un dominio despótico sobre estos últimos, sino que debe haber una cierta armonización entre los fines de la naturaleza y el hombre (22). El hombre puede y debe administrar la naturaleza para no generar la destrucción injustificada de la misma. No obstante, hay un problema cuando se pretende eliminar la diferencia entre los seres humanos y las otras especies: Si todas las especies son iguales, no hay fundamento por el cual deban ser respetadas unas por las otras, pues ante tal igualdad todas deberán sujetarse al devenir, cuya fuerza permita triunfar a unas por encima de las demás (22).

Por consiguiente, en esa lógica, el hombre, que está más capacitado para intervenir, podría hacerlo sin preocuparse, o aducir que se afecta a los otros vivientes en su dignidad. Curiosamente la dignidad humana viene dada por la capacidad de autodominio y racio- 
Bioética global: ¿nuevos argumentos sobre los derechos animales?

nalidad que permite eso: tratar con racionalidad el mundo natural y sin abusar de él, pero ello supone reconocer la dignidad propia humana. La pregunta que surge, en otro sentido, es si los «derechos de los animales» surgen por la capacidad de los mismos de tener responsabilidades o sólo por el hecho de coexistir entre ellos (22). Cualquier gobierno no despótico reconoce que el ser humano está con la naturaleza y, a la vez, que es más que «mera» naturaleza: el hombre no está finiquitado en la especie. El hombre es el único que hace historia personal y se conforma en el actuar libre y racional. No se trata, pues, de sobrenaturalizar al hombre, sino de corresponsabilizarlo: sólo los seres racionales y con voluntad son, estrictamente hablando, responsables de algo; es decir, sujetos morales.

\section{Algunas observaciones finales sobre la singularidad de lo humano}

El presupuesto de la inconsistencia teórica sobre la naturaleza únicamente gradual del ser humano y los animales es exactamente el tópico que surge en todos los argumentos presentados. No producir sufrimiento innecesario a los animales no humanos se ha de hacer por un deber indirecto para con ellos, en cuanto que deshumaniza a las personas (22).

Puede insistirse en que sigue siendo un argumento ad hoc sólo para mantener el prejuicio. En efecto, el argumento basado en la diferencia de trato por la pertenencia a la especie es eso, sólo un prejuicio poco intuitivo.

No obstante, a mi parecer, la «superposición de las especies» es la piedra de toque de los argumentos sobre los derechos de los animales. Si consideramos las características empíricas de las capacidades racionales sólo como actualizaciones, sin una capacidad radical de fondo, entonces no hay diferencia más que de grado. Así, el hecho de que el hombre fabrique, por ejemplo, herramientas no

Medicina y Ética - Enero-Marzo 2022 - Vol. 33 - Núm. 1 
marcaría diferencia entre los animales no humanos, ya que podría explicarse como una diferencia de grado. Pero esto es más complejo. Sin embargo, los opositores han señalado respecto del ejemplo de las herramientas que, sin duda, los animales usan herramientas, pero no poseen una capacidad abstractiva de concebir las herramientas como herramientas o de usar herramientas para crear otras. Ello implica una capacidad de poseer conceptos universales, de abstracción $(23,24,25)$. Si entendemos la capacidad del hombre de conocer y fabricar herramientas en cuanto tales y con la misma concepción de «herramienta», la diferencia no parece de grado.

Otro argumento en contra de la igualación ontológica es que la persona es incomunicable; es decir, es única. Si la incomunicabilidad se entiende sólo como ubicación espacial más o menos compartible, es bastante claro que un gato, por ejemplo, es un gato y no otro, y en ese sentido es un gato único (23). Pero, la incomunicabilidad personal significa insustituible ontológicamente; es decir, ser plenamente autónomo en cuanto puede proponerse fines. Implica una capacidad radical, como se comentó antes, en donde surgen la inteligencia y la voluntad como capacidades inmateriales, y no sólo como manifestación de resolver problemas (22). La naturaleza racional característica de las personas es su capacidad de autodirigirse fuera del instinto, por decirlo así: A diferencia de los nombres comunes y propios, el término «persona» nombra directamente el acto de ser, que es lo que hace subsistir a la persona. Ese constitutivo formal hace que la persona exista por si y en sí, y hace que la persona sea una realidad subsistente de naturaleza racional (23).

Puede insistirse en que hay confusión entre el modo de conocer y el de ser. En efecto, descubrir voluntariedad, capacidad de reír, capacidad de pensarse como un yo, son las que permiten saber que estamos ante una persona, pero no son su constitución, ya que deriva de una capacidad radical: porque somos personas podemos hacer eso, y no al revés (24).

También se ha producido una discusión en torno al lenguaje humano y animal, insistiendo unos en que el lenguaje animal sólo es 
Bioética global: ¿nuevos argumentos sobre los derechos animales?

una diferencia de grado con el humano, y defendiendo otros que tiene un nivel de complejidad que no puede ser explicada de esa forma $(24,25)$.

De cualquier manera, el fondo de la discusión termina siendo la ontología, la cual surge en todos los argumentos, incluso en los no utilitaristas, como podría ser el de Nussbaum (26). Así lo resume José Justo Megías:

Quienes se empeñan en situar al animal y al ser humano en un mismo plano del ser, en razón de que poseen algunas de esas capacidades, soslayan que los primeros las tienen de forma parcial y que ninguno alcanza el grado en que se presentan en el ser humano. La clave está en su modo de ser, en la compleja racionalidad y libertad..., cualidades que se manifiestan en capacidades concretas que le permiten hacerse cargo de su vida en el entorno en el que convive junto a los demás, algo fuera del alcance de cualquier otro animal conocido. Cuándo y cómo aparecieron y se desarrollaron estas cualidades y capacidades que nos diferencian de los animales son cuestiones difíciles de responder... Pero lo cierto es que sólo nosotros las tenemos, o sólo nosotros las tenemos en un grado tan cualificado que nos hace ser distintos de los animales en el modo de ser (25).

En otras palabras, de nuevo es el nivel ontológico el que se manifiesta en diversas cualidades como la autoconciencia, la capacidad ética, el dominio del lenguaje, la cultura y el sentido de la muerte y la trascendencia. Puede verse un resumen de todas esas características, junto con algunas discusiones recientes, en el texto citado de José Justo Megías (25), en el texto de Renée Mirkes (24) y en Rodrigo Frías (27), que lo aborda desde la perspectiva del Magisterio de la Iglesia Católica.

\section{Conclusiones}

Los argumentos relativamente recientes acerca de los supuestos derechos de los animales no se han modificado sustancialmente 
respecto de los argumentos tradicionales contra el especismo. Parten de supuestos tales como que la distinción entre lo humano y lo no humano es meramente un asunto de agregación y complejidad material. Se considera que no hay diferencia radical ente la inteligencia y voluntad, siendo estas facultades una cuestión de grados. $\mathrm{El}$ argumento del profesor Jacquet trata de ser un ajuste del argumento clásico de la superposición de las especies. El argumento moral, que no está correctamente fundamentado, es un razonamiento desviado que es más débil que el contrario; luego entonces debe aceptarse el principio igualitarista. No obstante, se ha tratado de mostrar que en el fondo los presupuestos metafísicos son los mismos de siempre: si el hombre posee facultades espirituales y es sujeto de sí mismo, será radicalmente diferente de los animales no humanos.

Los argumentos recientes respecto de los derechos de los animales siguen suponiendo la superposición de las especies, así como el principio de que la diferencia entre los humanos y los animales sólo es cuestión de grado. Asimismo, la defensa de la diferencia y justificación especista sigue siendo la misma: hay una diferencia radical entre seres humanos y animales. La emergencia de lo humano es un salto cualitativo que puede justificar la utilización de los animales no humanos para las necesidades humanas, aunque no en sentido despótico. El argumento de la madre Tierra no prueba que los animales no humanos y el hombre sean iguales, pero sí muestra que el dominio descontrolado del hombre sobre la naturaleza perjudica, en primer lugar al hombre mismo, y en segundo término a los animales. No obstante, otro tema a discutir son los límites y criterios con los que el hombre debe tratar al resto de los seres vivos.

\section{Referencias bibliográficas}

1. Holm S, Williams-Jones, B. Global bioethics, myth or reality? BMC Med Ethics. 2006; 7: 10. https://doi.org/10.1186/1472-6939-7-10 
Bioética global: ¿nuevos argumentos sobre los derechos animales?

2. Borry P, Schotsmans $P$ \& Dierickx K. How international is bioethics? A quantitative retrospective study. BMC Med Ethics. 2006; 7: 1.

https://doi.org/10.1186/1472-6939-7-1

3. Nohama Norton, Da Silva Jefferson Soares, Simão-Silva Daiane Priscila. Desafíos y conflictos bioéticos del CovID-19: contexto de salud global. Rev. Bioét. (Consultado el 10 de mayo de 2021). 2020; 28(4): 585-594. Disponible en: https://www. scielo.br/j/bioet/a/Q7QYzT6FQkvTgDcZybfGBKc/?lang=pt

https://doi.org/10.1590/1983-80422020284421

4. Vargas CE. Bioética y derechos animales: análisis sobre la consideración moral hacia los animales no-humanos (Maestría). Universidad del Azuay, Ecuador. 2020.

5. Pessini L. Bioetica global en tiempos de incertidumbres, perplejidades y esperanzas. S.f. Disponible en: https://www.camilliani.org/wp-content/uploads/2019/03/ bioetica.pdf

6. Vargas F. Hacia una fundamentación de la Bioética Ambiental desde la visión de Fritz Jahr, Aldo Leopold y Van Rensselaer Potter. Rev. Col. Bioet. (Consultado el 12 de mayo de 2021). 5 de diciembre de 2020; 15(2). Disponible en: https:// masd.unbosque.edu.co/index.php/RCB/article/view/3009

https://doi.org/10.18270/rcb.v15i2.3009

7. Jahr F. Die Wissenschaft vom Leben und Sittenlehre. Die Mittelschule. 1926; 40: 604-605. La ciencia de la vida y la enseñanza de la moral. Viejos descubrimientos bajo una nueva luz. Aesthethika. (Consultado el 12 de mayo de 2021). 2013; 8(2): 12-17. Disponible en: http://www.aesthethika.org/La-ciencia-de-la-vida-y-la

8. El imperativo bioético de Fritz Jahr. Una ética del respeto hacia los animales y las plantas por su cercanía con los seres humanos. Vida y Ética. 2020; 21: 1. Disponible en: https://erevistas.uca.edu.ar/index.php/VyE/article/view/3419

9. Roa-Castellanos R, Bauer C. Traducción de los textos sobre el imperativo bioético. Revista Latinoamericana de Bioética. (Consultado el 12 de mayo de 2021). Julio-diciembre de 2009; 9(2): 92-105. Disponible en: https://revistas.unimilitar.edu.co/index.php/rlbi/article/view/1063/801

10. Papa Francisco. Laudato Si. Disponible en: https://www.vatican.va/content/ francesco/es/encyclicals/documents/papa-francesco_20150524_enciclica-laudato-si.html

11. Aquino T. Suma de Teología. Disponible en: https://hjg.com.ar/sumat/c/c64. html\#a1

12. Vargas C. Bioética y derechos animales: Análisis sobre la consideración moral hacia los Animales no humanos (Tesis). Universidad de Azuay, Ecuador; 2020. Disponible en: http://dspace.uazuay.edu.ec/handle/datos/10314

13. Regan T. A case for animal rights. En M.W. Fox \& L.D. Mickley (Eds.). Advances in animal welfare science. Washington, DC: The Humane Society of the United States. 1986/87; 179-189. https://doi.org/10.1007/978-94-009-3331-6_15

14. Finnis J. Un frágil argumento en favor de la eutanasia. Réplica a John Harris. En La Eutanasia Examinada. México: FCE, 2004.

15. Jaquet F. A debunking argument against speciesism. Synthese. 2021; 198. https://doi.org/10.1007/s11229-019-02080-5

Medicina y Ética - Enero-Marzo 2022 - Vol. 33 - Núm. 1 


\section{J. E. Gómez Álvarez}

16. Lutz, Matthew and James Lenman. «Moral Naturalism». The Stanford Encyclopedia of Philosophy (Spring 2021 Edition), Edward N. Zalta (ed.). Disponible en: https://plato.stanford.edu/archives/spr2021/entries/naturalism-moral/>

17. Ocampo M. Reflexiones metafísicas sobre la ley moral en Santo Tomás de Aquino. Rev. Chil. Estud. Mediev. 2019; 15: 29-41. https://doi.org/10.4067/S0719-689X2019000100029

18. Maluf F, Calaça I, Freitas P, Augusto S. La naturaleza como sujeto de derechos: análisis bioético de las Constituciones de Ecuador y Bolivia. Rev. Latinoam. Bioet. (Consultado el 28 de mayo de 2021). 21 de noviembre de 2017; 18(34-1): 155-171. Disponible en: https://revistas.unimilitar.edu.co/index.php/rlbi/article/ view/3030 https://doi.org/10.18359/rlbi.3030

19. Argüello L. Los derechos de los animales y el nuevo paradigma del constitucionalismo latinoamericano. Revista Direitos Humanos \& Sociedade. 2019; 2: 1.

20. Valera L, Vidal G, Leal Y. Más allá de la aplicación. El caso de la ética ambiental. Tópicos México. (Consultado el 28 de mayo de 2021). 30 de mayo de 2021; 0(60): 437-460. Disponible en: https://revistas.up.edu.mx/topicos/article/view/1122 https://doi.org/10.21555/top.v0i60.1122

21. UNESCO. Declaración universal sobre Bioética y Derechos Humanos. 2005. http://portal.unesco.org/es/ev.php-URL_ID=31058\&URL_DO=DO_TOPIC\& URL_SECTION=201.html

22. Velázquez H. ¿Qué es naturaleza? México: Porrúa. 2007.

23. Conderana JM. Tomás de Aquino y Peter Singer: acerca de la extensión del término «persona». Salmanticensis. 2019; 66: 241-262.

https://doi.org/10.36576/summa.106940

24. Mirkes R. The wrongs of animal rights. The National Catholic Bioethics Quartely. 2003; 3(2): 287-307. https://doi.org/10.5840/ncbq20033255

25. Megías J. Ser humano y animales: estatuto ontológico y jurídico diferentes. Cuadernos de Bioética. 2020; 31(101): 59-70. https://doi.org/10.30444/CB.52

26. Chávez J. ¿Deben tomarse en serio los llamados derechos de los animales? Un análisis a partir del enfoque de Martha Nussbaum. Prudentia luris. 2017; 83.

27. Frías R. La cuestión animal: El Magisterio de la Iglesia católica en el contexto del debate actual. Veritas. 2014; 30: 105-126.

https://doi.org/10.4067/S0718-92732014000100006

Esta obra está bajo licencia internacional Creative Commons Reconocimiento-NoComercial-Compartirlgual 4.0. 